\title{
Modelagem Didático-científica: integrando atividades experimentais e o processo de modelagem científica no ensino de Física ${ }^{+*}$
}

Leonardo Albuquerque Heidemann ${ }^{1}$

Ives Solano Araujo ${ }^{2}$

Eliane Angela Veit ${ }^{3}$

Instituto de Física - UFRGS

Porto Alegre - RS

\section{Resumo}

A forma dissociada como teoria e prática são frequentemente tratadas no ensino de Física contribui para que os estudantes tenham dificuldades para utilizar os conhecimentos científicos para representar eventos reais, que não são idealizados como os eventos abordados na maior parte dos problemas propostos nos livros-texto usuais. Entendendo que o domínio do processo de modelagem científica é fundamental para que os estudantes aprendam Ciências, aprendam sobre Ciências e aprendam a fazer Ciências, Brandão, Araujo e Veit se amparam na Teoria dos Campos Conceituais de Vergnaud e na concepção de modelagem científica de Bunge para propor um referencial teórico-metodológico para a modelagem no Ensino de Física intitulado de Modelagem DidáticoCientífica (MDC). Os autores defendem a tese de que o processo de modelagem científica pode ser considerado um campo conceitual subjacente aos campos conceituais específicos da Física. Para isso, eles explicitam conhecimentos associados com o enfrentamento de problemas que envolvem o uso, a exploração e a validação de versões didáticas de modelos científicos. No entanto, não é objetivo desse referencial esclarecer como conceitos especificamente relacionados com o processo de con-

\footnotetext{
${ }^{+}$Didactical-Scientific Modelling: integrating experimental activities and the process of scientific modelling in the teaching of Physics

* Recebido: junho de 2015.

Aceito: novembro de 2015.

1 E-mail: leonardo@heidemann.com.br

2 E-mail: ives@if.ufrgs.br

${ }^{3}$ E-mail: eav@if.ufrgs.br
} 
trastação empírica se vinculam com os conceitos mais gerais relacionados com a modelagem científica. Para preencher tal lacuna, apresentamos neste artigo uma expansão desse aporte teórico-metodológico em que, com base nas concepções de Bunge sobre a contrastação de ideias científicas, inserimos o trabalho experimental no campo conceitual associado ao processo de modelagem didático-científica e derivamos invariantes operatórios de referência para esse campo conceitual. Por fim, exemplificamos seu uso para amparar o delineamento e a condução de atividades experimentais com enfoque no processo de modelagem científica e discutimos implicações para a pesquisa em ensino de Física.

Palavras-chave: Modelagem científica; Atividades experimentais; Modelagem didático-científica.

\begin{abstract}
The dissociated way with which the theory and practice are often treated in Physics teaching contributes to students' difficulties in using scientific knowledge to represent real events, which are not idealized situations as the events presented in most textbook problems. Considering that the process of scientific modeling is of fundamental importance for students to learn Science, about Science and how to do Science, Brandão, Araujo and Veit, supported by Vergnaud's Theory of Conceptual Fields and by Bunge's concept of scientific modeling, propose a theoreticalmethodological framework for modeling in Physics Education named Didactical-Scientific Modeling (DSM). The authors defend the thesis that it is possible to consider the process of scientific modeling as a conceptual field underlying the specific conceptual fields of Physics. They elucidate knowledge associated to the facing of problems that involve the use, exploration and validation of didactical versions of scientific models. However, the goal of this framework is not to explain how the concepts related to empirical testability are connected to scientific modeling concepts. In order to fill this gap, we present in this article an expansion of this theoretical-methodological framework based on Bunge's concepts on contrasting scientific ideas. In this regard, we insert experimental work concepts in the conceptual field associated to the process of didactical-scientific modeling. Lastly, we exemplify its use in order to support the design and execution of experimental activities focused on the scientific-didactical process, and we also discuss some implications for future research in Physics Education.
\end{abstract}


Keywords: Scientific modeling; Experimental activities; Didacticalscientific modeling.

\section{Introdução}

"Professor, como eu devo responder estas questões? De acordo com o que você nos ensinou, ou da forma que penso sobre estas coisas?". Tal questão, levantada por um aluno do professor Eric Mazur (1997, p. 4) da Universidade de Harvard (EUA), evidencia a forma como uma significativa parcela dos estudantes interpreta a disciplina de Física: um punhado de teorias com pouca ou nenhuma conexão com a realidade. Identificar fatores que explicam tal situação não é tarefa complicada. O ensino de Física tem sido frequentemente pautado pela resolução de problemas acadêmicos que fazem referência exclusivamente a eventos e objetos já idealizados, nos quais são desprezados diversos aspectos da complexidade característica dos eventos reais. Com isso, o significado dos conhecimentos abordados nas aulas torna-se, em grande parte, restrito para as situações enfrentadas dentro das paredes da sala de aula.

Esse cenário explica parte dos motivos pelos quais os estudantes têm dificuldades para utilizar conceitos, leis e princípios relacionados aos diferentes campos da Física na resolução de autênticos problemas sobre eventos reais que, por não serem idealizados, abarcam toda a complexidade da realidade. Nesses problemas, é necessário, por exemplo, idealizar os eventos investigados para torná-los abordáveis à luz de conhecimentos científicos. Nesse processo, é preciso adotar uma postura crítica e reflexiva avaliando a adequação das decisões de desprezar ou de considerar elementos do evento investigado para a resolução do problema enfrentado. Como auxiliar os alunos no enfrentamento desse tipo de problema?

Para Vergnaud, "um dos problemas do ensino é desenvolver ao mesmo tempo a forma operatória do conhecimento, isto é, o saber-fazer, e a forma predicativa do conhecimento, isto é, o saber explicitar os objetos e suas propriedades" (VERGNAUD, 1996, p. 13). Concordando com essas ideias, Brandão, Araujo e Veit $(2008$; 2011; 2012) se aliam aos pesquisadores que defendem o enfoque no processo de modelagem científica como uma forma de vincular teorias e realidade no ensino de Ciências (e.g., PIETROCOLA, 1999; CUPANI; PIETROCOLA, 2002; BOULTER; GILBERT, 2000; HESTENES, 2006; KOPONEN, 2007; OH; OH, 2012; LOUCA; ZACHARIA, 2012). Os autores adotam a Teoria dos Campos Conceituais de Vergnaud (1993; 1996; 1997; 1998; 2009; 2012; 2013a; 2013b) e a concepção de modelagem científica de Bunge $(1974 ; 1980 ; 1989 ; 2010)$ para argumentar que, no processo de representação da realidade, a modelagem científica pode ser entendida como um campo conceitual subjacente aos campos conceituais da Física (BRANDÃO; ARAUJO; VEIT, 2011; 2012). Defendem ainda que é fundamental que sejam propostos no ensino de Física problemas menos idealizados para que os estudantes enfrentem situações que instiguem a conceitualização do real, e ampliem seu domínio do campo conceitual da modelagem científica. Essa ampliação, em acordo com as ideias de Vergnaud (1993), é assumida como 
um processo progressivo, envolvendo rupturas, avanços e retrocessos. O domínio de um estudante de um campo conceitual é parcial, sendo ampliado na medida em que novas situações são enfrentadas.

Procurando esclarecer como os conhecimentos são mobilizados pelos estudantes quando enfrentam problemas não idealizados em Física, Brandão, Araujo e Veit $(2011 ; 2012)$ mostram que o processo de modelagem científica pode ser visto como um campo conceitual subjacente aos domínios dos campos conceituais específicos da Física, propõem uma estrutura conceitual de referência para esse campo conceitual, e apresentam invariantes operatórios de referência para o enfrentamento de situações que dão sentido aos conceitos que constituem essa estrutura conceitual.

A articulação teórica realizada por Brandão, Araujo e Veit (idem) resultou em um referencial teórico-metodológico para a modelagem no Ensino de Física denominado de Modelagem Didático-Científica (MDC). A MDC proporciona uma fundamentação consistente para professores e/ou pesquisadores de Física que procuram delinear, investigar e/ou avaliar atividades de ensino com enfoque no processo de modelagem científica. No entanto, esses autores tratam do processo de modelagem científica em um âmbito geral, não incluindo especificidades do trabalho experimental dentro do campo conceitual da modelagem didático-científica. Em função disso, conceitos como de evidência, predição e experimento, indispensáveis no processo de contrastação empírica dos modelos científicos, não são considerados na estrutura conceitual de referência proposta para a MDC. A ausência desses conceitos, assim como de invariantes operatórios e de situações relacionadas ao trabalho experimental, constitui-se em uma lacuna que ganha importância quando o processo de modelagem científica abarca situações que envolvem o fazer experimental.

Neste artigo, buscamos preencher essa lacuna. Partimos das concepções de Bunge sobre o papel das operações empíricas no processo de modelagem para desenvolver uma expansão do campo conceitual da modelagem didático-científica, incluindo conceitos, teoremas e situações particularmente relacionadas com o trabalho experimental. Esse referencialteórico metodológico, expandido em relação ao proposto por Brandão, Araujo e Veit (idem), tem potencial para:

i) orientar investigadores que pretendem elucidar os processos cognitivos acionados pelos estudantes quando enfrentam situações que envolvem construção, exploração e validação de modelos científicos; e

ii) amparar professores que pretendem delinear, desenvolver e avaliar atividades de ensino de Física frutíferas para que os estudantes desenvolvam competências relacionadas com a modelagem de eventos reais, vinculando teoria e prática nas aulas de Física, como discutiremos na Seção 5.

Na próxima seção, apresentamos sucintamente as ideias centrais da MDC propostas por Brandão, Araujo e Veit (idem). Na Seção III, discutimos o processo de contrastação empírica na concepção de Bunge $(1989 ;$ 1998; 2010) e, na Seção IV, mostramos como os conceitos 
envolvidos nesse processo podem ser vinculados à MDC. Ainda nessa seção, apresentamos doze invariantes operatórios de referência associados ao fazer experimental. Alguns deles são ilustrados na Seção V com um exemplo específico, seguido da seção de comentários finais na qual são apresentadas implicações da MDC para a área de pesquisa em Ensino de Física.

\section{Modelagem Didático-científica segundo Brandão, Araujo e Veit}

Modelagem didático-científica pode ser compreendida como "um instrumento teórico-metodológico que orienta as ações do sujeito-em-situação quando ele, de alguma forma, precisa modelar situações físicas no contexto educacional" (BRANDÃO; ARAUJO; VEIT, 2012).

Quando um sujeito enfrenta problemas que demandam a construção de representações simplificadas de eventos reais, necessita mobilizar esquemas de ação particularmente associados com o processo de modelagem científica. Esses esquemas são invariantes frente a uma classe de situações de modelagem e compreendem conhecimentos especificamente relacionados com o processo de modelagem científica, ou seja, conceitos e teoremas que possibilitam que o indivíduo reconheça os elementos pertinentes das situações que envolvem a construção, o uso e a validação de modelos científicos. Tais conhecimentos são denominados de invariantes operatórios.

Em suma, existe um conjunto entrelaçado de situações, conceitos, teoremas, esquemas e invariantes operatórios especificamente relacionados com o processo de modelagem científica, denominado de campo conceitual da modelagem científica. Esse campo conceitual é constituído por três conjuntos (BRANDÃO; ARAUJO; VEIT, 2012, p. 277):

i) um conjunto de situações físicas que dão sentido aos conceitos associados às no-
ções sobre modelos e modelagem científica em Física;
ii) um conjunto de invariantes operatórios de: a) caráter geral, associados à noção
de modelo e ao processo de modelagem científica em Física, e b) caráter específico,
associados aos conceitos da estrutura conceitual de referência; iii) um conjunto de representações simbólicas que podem ser usadas para indicar esses invariantes.

Para definir os conceitos que compõem o campo conceitual da modelagem didático-científica e suas principais relações, Brandão, Araujo e Veit propõem a Estrutura Conceitual de Referência (ECR) ${ }^{4}$ mostrada na Fig. 1, inspirada na concepção de modelagem de Bunge. Passamos a descrevê-la.

\footnotetext{
${ }^{4}$ Estrutura Conceitual de Referência é uma expressão cunhada por Rita Otero (2006, p. 27) para designar o "conjunto dos conceitos, das relações entre eles, dos princípios, das asserções de conhecimento e das explicações relativas a um campo conceitual, como ele é formulado, debatido e acordado nas discussões e nos textos especializados próprios de uma determinada comunidade científica de referência".
} 


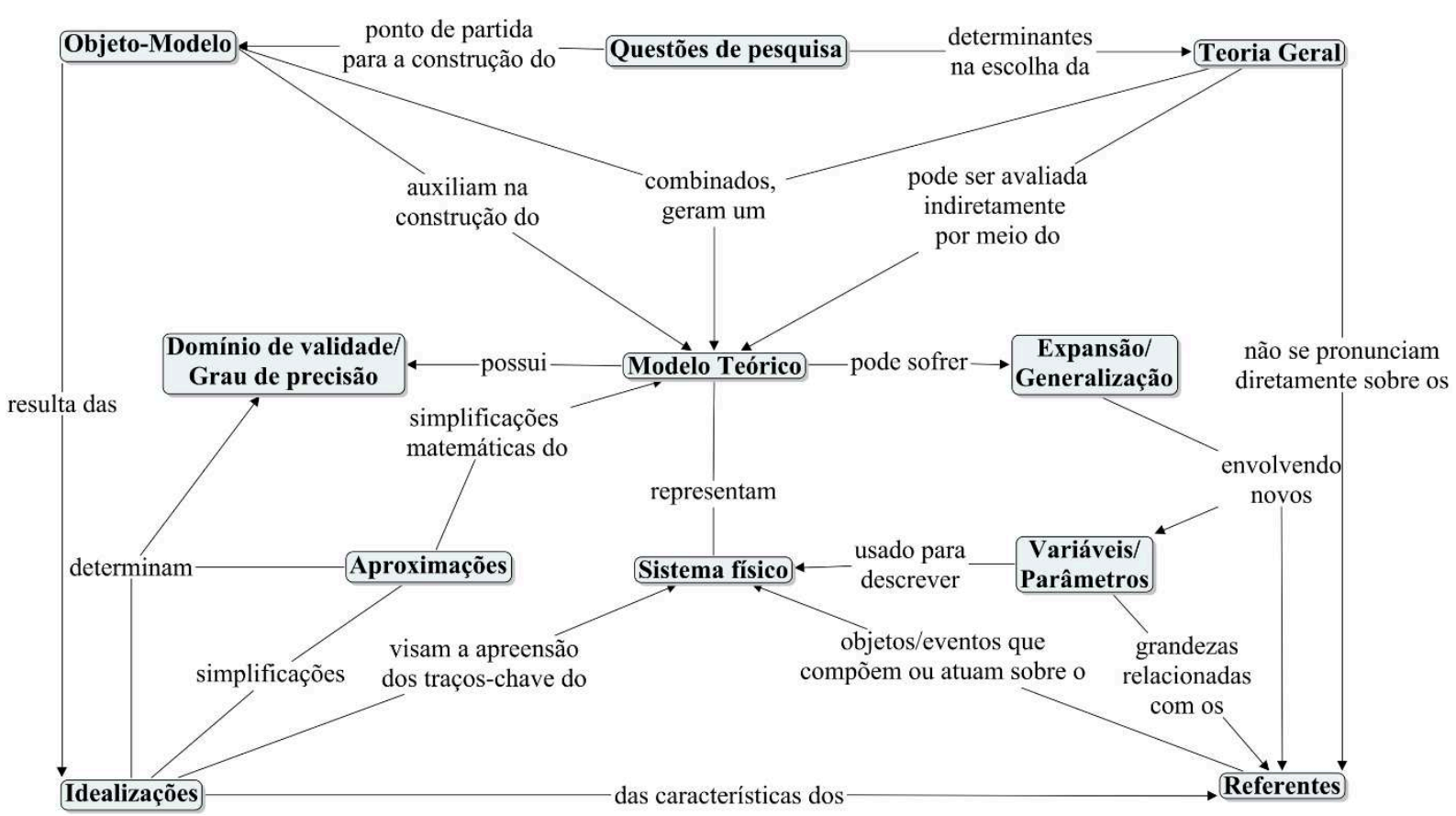

Fig. 1 - Estrutura Conceitual de Referência associada à noção de modelo e ao processo de modelagem científica em Física (BRANDÃO; ARAUJO; VEIT, 2012, p. 277).

Refletindo a concepção bungeana sobre o processo de modelagem científica, o conceito de questão de pesquisa é central na ECR representada na Fig. 1. É focado no propósito de responder a uma questão sobre um evento do mundo real que, segundo Bunge, é realizado o delineamento de um objeto-modelo (também chamado de modelo conceitual), ou seja, de uma representação conceitual esquemática do evento real ou suposto como tal (BUNGE, 1974). Para isso, simplifica-se a descrição do mundo real e definem-se os traços-chave dos objetos concretos (os elementos reais pertinentes para a confecção do modelo científico). Esses procedimentos são enfatizados na ECR por meio dos vínculos estabelecidos entre os conceitos de questões de pesquisa, de objeto-modelo e de idealizações. Exemplificando, podemos mencionar o objeto-modelo de pêndulo simples, que consiste em um corpo pontual suspenso por um fio inextensível e inflexível de massa desprezível oscilando em um plano vertical em torno de uma posição de equilíbrio. O pêndulo simples não existe na natureza: todos os fios possuem elasticidade e massa; todos os corpos possuem dimensões, mas esse modelo pode ser usado para representar diversos sistemas físicos.

Via de regra, os cientistas procuram usar os objetos-modelo para construir modelos teóricos com base em teorias gerais, e esse procedimento é destacado na ECR por meio das conexões dos conceitos de objeto-modelo, de teoria geral e de modelo teórico. O objetomodelo de pêndulo simples, por exemplo, pode ser explorado em conjunto com a mecânica newtoniana, que é uma teoria geral, para se construir um modelo teórico. Cabe destacar que frequentemente a escolha de uma teoria geral e a construção de um modelo conceitual não são processos desassociados; usualmente modelos conceituais são construídos à luz da teoria geral pertinente para responder à questão de pesquisa desejada. 
Segundo Bunge (idem), as teorias gerais isoladamente (e.g., mecânica newtoniana) não fornecem predições sobre eventos particulares. Já os modelos teóricos sempre versam, em última análise, sobre objetos reais 5 ou supostos como tais. Estes objetos reais são chamados de referentes. Com o intuito de enfatizar a relação mediada entre as teorias gerais e os referentes dos modelos teóricos, é destacado na estrutura conceitual do campo conceitual da modelagem didático-científica que as teorias gerais não se pronunciam diretamente sobre os referentes dos modelos teóricos.

Na Fig. 1, os modelos teóricos estão relacionados com os processos de expansão e de generalização. Tal vínculo é estabelecido em função de que, para Bunge (idem): i) todo modelo teórico se refere a um determinado objeto-modelo que pode ser expandido por meio de alterações em suas idealizações ou em seus referentes, e ii) os modelos teóricos podem ser generalizados, passando a representar eventos diferentes do evento para o qual ele foi originalmente construído. Além disso, essa ECR relaciona os modelos teóricos com os conceitos de domínio de validade e de grau de precisão. Essas conexões são estabelecidas em decorrência de que um modelo teórico nunca produzirá uma "imagem especular" da realidade, se não for por outro motivo, pelo menos porque são construídos a partir de um objeto-modelo, ou seja, de uma descrição simplificada e inteiramente hipotética dos referentes que se busca apreender. O grau de precisão e o domínio de validade dos modelos teóricos dependem, portanto, da complexidade dos objetos-modelo utilizados nas suas construções.

Seguindo as ideias propostas na Teoria dos Campos Conceituais, os conceitos sintetizados nessa ECR são entendidos aqui como os principais conceitos-em-ação do campo conceitual da modelagem didático-científica utilizados nos esquemas de ação mobilizados pelos estudantes em situação de modelagem. Complementando os principais invariantes operatórios, Brandão, Araujo e Veit (2011, p. 528-529) identificam treze teoremas-em-ação para o campo conceitual da modelagem didático-científica, sendo quatro de caráter geral, associados aos conceitos de modelo e modelagem científica, e nove de caráter específico, associados aos conceitos da ECR. Por exemplo, associado ao conceito de idealização, o invariante operatório de caráter específico proposto é: "Dado um sistema físico, decidir quais dos seus traços-chave apreender".

Ainda que Brandão (2012) destaque que o campo conceitual da modelagem didáticocientífica abrange atividades experimentais que enfatizam o papel mediador dos modelos entre teorias e experimentos, não estava em seus objetivos pormenorizar os esquemas de ação utilizados pelos estudantes quando defrontados com as situações relacionadas com o trabalho experimental. Para aprofundar a concepção do campo conceitual da modelagem didáticocientífica proposta por Brandão, Araujo e Veit, discutimos na próxima seção as concepções de Bunge sobre a contrastação empírica.

\footnotetext{
5 Bunge (1974) entende que a Ciência procura tratar os objetos reais ou supostos como tais de maneira objetiva, ou seja, separando-os do sujeito e considerando-os invariáveis com respeito ao operador.
} 


\section{Concepções de Bunge sobre a contrastação empírica}

A validação dos modelos científicos é um aspecto central do processo de modelagem científica. Não basta ao cientista construir modelos teóricos com base em teorias gerais e objetos-modelo se esses modelos não passarem por um processo de validação que evidencie os seus graus de precisão e seus domínios de validade. Nesse processo, ainda que o uso do computador possa contribuir emulando o comportamento dos modelos científicos, o caminho natural é o da contrastação empírica, que pode ser entendida como um dos procedimentos envolvidos na modelagem científica. A questão que se coloca, então, é: Como os conceitos específicos do processo de contrastação empírica se vinculam aos conceitos centrais da modelagem científica?

Para responder à questão acima, optamos por, estabelecendo uma continuidade aos estudos de Brandão, Araujo e Veit, nos apoiar nas ideias de Bunge sobre o trabalho experimental. Mais especificamente, com o objetivo de expandir a concepção do campo conceitual da modelagem didático-científica, efetuamos inicialmente uma análise dos livros de Bunge (1989; 1998; 2010) buscando aprofundar nosso entendimento sobre como esse autor concebe a contrastação empírica das ideias científicas. O resultado dessa análise será apresentado nesta seção e utilizado na Seção IV para a ampliação da Estrutura Conceitual de Referência do campo conceitual da modelagem didático-científica, incluindo os principais conceitos e relações específicos do trabalho empírico.

\section{III.1 As operações empíricas segundo Bunge}

As experiências científicas podem ser conduzidas com diferentes objetivos e metodologias. Procurando elucidar o delineamento e a execução dessas experiências, Bunge estabelece que todas elas são constituídas por uma composição de diferentes operações empíricas denominadas: i) observações; ii) medições; e iii) experimentos (BUNGE, 1989). Passamos agora a apresentar algumas das características de cada uma dessas operações.

A observação, segundo Bunge, é uma operação empírica básica, pois tanto as medições quanto os experimentos envolvem observações de fatos. Cabe ressaltar, no entanto, que a definição usada por ele restringe o uso do termo observação ao sentido estrito de observação direta. Reações químicas ou sentimentos, por exemplo, só são observáveis indiretamente, ou seja, só são identificados por meio de inferências hipotéticas derivadas de observações diretas. Nesses exemplos, as observações podem, respectivamente, envolver a análise da cor de uma substância ou uma avaliação da expressão facial de um indivíduo (idem).

Duas características são intrínsecas às observações científicas: são percepções intencionadas e ilustradas. Intencionadas ou deliberadas porque são realizadas com um objetivo pré-estabelecido. Ilustradas porque são guiadas em algum nível por um conhecimento prévio. Essas particularidades das observações científicas elucidam os motivos pelos quais o indivíduo leigo pode falhar quando realiza uma observação científica. Primeiramente, em função de 
não possuir o olhar treinado do especialista, ele pode nem conseguir identificar o que precisa observar. Em seguida, ainda que testemunhe o objeto, a falta de um conhecimento científico adequado pode implicar no não reconhecimento do evento observado, o que faz com que ele não seja capaz de apreender os aspectos mais importantes da observação. Por fim, ainda que tenha identificado aspectos do fato observado de forma satisfatória, o leigo provavelmente será incapaz de interpretá-los teoricamente. Fica evidente, portanto, que as observações são amparadas em marcos teóricos pré-estabelecidos (idem).

Bunge ressalta que as observações são insuficientes para se alcançar os mais significativos objetivos da Ciência (idem). O conhecimento factual profundo e preciso necessita de um apoio empírico baseado em medições e experimentos. Isso decorre de que a maioria dos eventos nos quais os cientistas se debruçam não é observável diretamente. Usualmente eles são inferidos por meio de hipóteses que os relacionam com medições de fatos perceptíveis. Exemplificando essas relações, Bunge destaca que as roupas, o(s) automóvel(veis) e a maneira de se manifestar de um homem integram um conjunto de indicadores objetivos do seu status social, que é em si mesmo inobservável. Esses indicadores de correspondentes inobserváveis são postulados por teorias, ou seja, por sistemas hipotéticos-dedutivos.

Com o objetivo de aprofundar a discussão sobre indicadores observáveis de fatos inobserváveis, Bunge utiliza o conceito de função. $\mathrm{O}$ autor denomina de $U$ um dos membros de um conjunto de valores possíveis de uma propriedade inobservável, que pode ser, por exemplo, a pressão atmosférica. Por outro lado, ele denomina de $O$ um membro de um conjunto de valores de uma propriedade diretamente observável que, no caso exemplificado, pode ser a altura de uma coluna barométrica. Supomos então que existe uma função que relaciona o valor de $U$ com o valor de $O$, ou seja, uma função $f(O)=U$. Desse modo, os valores de $U$ podem ser inferidos por meio dos valores de $O$. No exemplo apresentado, a pressão atmosférica pode ser inferida por meio da altura de uma coluna barométrica. Cabe ressaltar que tanto $U$ como $O$ são conceitos teóricos. No entanto, ao contrário de $U, O$ representa uma propriedade observável, e a relação entre tais conceitos é em si mesma uma hipótese durante uma medição. Outro exemplo de relação entre grandezas observáveis e inobserváveis é a vinculação entre a velocidade angular de um anemômetro, que é uma propriedade observável, e a velocidade do vento, que é inobservável (idem).

A observação pura e simples, tanto direta quanto indireta, só é capaz de apreender alguns traços de um sistema concreto. Para torná-las precisas e mais claramente comparáveis, é preciso quantificá-las, ou seja, atribuir números a certas características observadas. Quando essa quantificação é feita, segundo Bunge, faz-se uma operação empírica de medição (idem).

O processo de medição envolve sempre ao menos um sistema macroscópico: o dispositivo de medição. Bunge destaca que, no nível macroscópico, não existem dois sistemas idênticos; mesmo que possam ser muito sutis, sempre haverá diferenças entre eles. Em consequência, é bastante improvável que sejam obtidos dois resultados de medições exatamente iguais. Bunge sintetiza isso dizendo que "os resultados de qualquer conjunto de medições 
cuidadosas são diferentes porque todos os sistemas implicados nesses processos estão submetidos a perturbações" (ibid., p. 778).

O experimento científico é, segundo Bunge, a terceira e mais rica operação empírica. Sua definição é bastante precisa: "Experimento é aquela classe de experiência científica na qual se provoca deliberadamente alguma mudança e se observa e interpreta seu resultado com alguma finalidade cognitiva" (ibidem, p. 819). Dito de outro modo, um experimento envolve um evento construído propositadamente e é conduzido centrado em um objetivo. Dessa forma, a ação de um indivíduo que aprecia despretensiosamente a beleza da Lua em um telescópio não é um experimento, pois tal ação não é realizada com uma finalidade cognitiva, já que o sujeito não procura a priori investigar algum fenômeno lunar, e não abrange um evento delineado por ele, já que, evidentemente, não foi realizado nenhum tratamento na Lua com o intuito de produzir algum fenômeno particular. Na sequência, destacaremos algumas das características tanto dos objetivos dos experimentos científicos como dos seus delineamentos.

Um dos aspectos centrais dos experimentos científicos é o controle de variáveis. Ao contrário dos fatos espontâneos, que são, na maioria dos casos, bastante complexos, os fatos experimentais são mais simples, o que os torna melhor observáveis. Isso ocorre porque os sistemas estudados em experimentos são construídos com base em um modelo teórico de referência. Desse modo, procura-se concentrar em torno de poucas variáveis, de modo a minimizar perturbações e irrelevâncias presentes em todo sistema natural (BUNGE, 1989). Vejamos um exemplo: suponha que um indivíduo quer avaliar a relação entre o período e o comprimento do fio de um pêndulo prevista pelo modelo newtoniano de pêndulo simples. Nesse caso, é natural que o investigador escolha usar, como arranjo experimental, um pêndulo com: i) um corpo suspenso muito pequeno em relação ao comprimento do fio que o sustenta; e ii) um fio pouco elástico e com massa pequena em relação à massa do corpo suspenso. Além disso, esse investigador provavelmente movimentará o pêndulo com pequenas amplitudes. O objetivo do investigador com essas escolhas é aproximar o seu arranjo experimental do objetomodelo que ampara o modelo teórico de referência do seu experimento. Fica evidente aqui que um experimento não é conduzido em um vazio teórico, mas sim dentro de um corpo de ideias que origina o problema a ser respondido e dirige o delineamento e a interpretação da investigação.

Vimos que o sistema concreto estudado em um experimento é, em maior ou menor medida, inserido em um meio artificial devido aos procedimentos realizados pelo pesquisador para que o arranjo experimental seja o mais fiel possível ao modelo teórico que ampara a investigação. Além disso, outro fator que torna o meio experimental artificial são os procedimentos de controle de variáveis. Refletindo sobre o exemplo anterior, é importante que o indivíduo que procura avaliar a influência do comprimento do fio no período de um pêndulo faça todas as suas medidas com o pêndulo elongado em um mesmo ângulo inicial, pois ele deseja que, dentro do possível, as alterações no período dos pêndulos investigados ocorram somente em função de variações do comprimento do fio de sustentação. Como o modelo teó- 
rico de referência do seu experimento, que é o modelo newtoniano de pêndulo simples, prevê que o período de um pêndulo depende da sua amplitude, o investigador necessitará controlar essa grandeza na sua pesquisa. Fica claro aqui o papel dos modelos teóricos na definição das variáveis que necessitam ser controladas nos experimentos científicos. Torna-se evidente também que o controle do experimentador ocorre tanto nos estímulos que ele precisa provocar no arranjo experimental, como no momento em que ele coloca o pêndulo para oscilar, quanto sobre o arranjo em si, quando ele procura minimizar efeitos não considerados no seu modelo teórico de referência. Em suma, um experimento é deliberado, conduzido e interpretado dentro de um corpo de ideias.

As ideias científicas são contrastadas por meio de processos que envolvem operações empíricas. Isso é aqui ilustrado destacando dois tipos de contrastação: i) a de hipóteses científicas; e ii) a de teorias científicas (idem). Passamos agora a apresentar as características mais importantes desses dois casos de contrastação empírica.

\section{III.2 A contrastação de hipóteses}

Na concepção de Bunge, as hipóteses são proposições que vão além das evidências (BUNGE, 1989; 1998). Em outras palavras, as hipóteses referem-se a fatos que não foram experimentados até o momento ou mesmo que não são suscetíveis de experimentação. Bunge apresenta um exemplo: um indivíduo observa que a direção da agulha de um voltímetro analógico conectado em um ramo de um circuito elétrico coincide com a marcação de 127 volts. A informação de que a direção da agulha coincide com a marcação de 127 volts é uma proposição observacional, pois ela não vai além do que foi observado pelo indivíduo. No entanto, é apenas uma hipótese a inferência de que, naquele circuito específico, existe uma corrente elétrica circulando, pois tal fato não é observável. Essa hipótese pode estar inclusive equivocada, pois, por exemplo, o voltímetro pode estar estragado.

Desse modo, fica claro que, apesar de se exigir em Ciência que as hipóteses sejam, em alguma medida, fundamentadas em conhecimentos prévios, elas não são diretamente contrastáveis. Por isso, o valor veritativo das hipóteses só pode ser avaliado por meio da contrastação direta de suas consequências em linguagem semiempírica (BUNGE, 1989). Analisaremos o que isso significa.

Consideremos a seguinte hipótese $h$ : o ar é um fluido que obedece às leis da hidrostática. Bunge ressalta que não existem operações empíricas suficientes que nos possibilitem avaliar essa proposição em sua totalidade, pois são inúmeras as consequências dessa hipótese e é inviável se investigar todo o ar presente na Terra. Entre as possíveis derivações de $h$, podem ser destacadas, por exemplo, a hipótese $h_{1}$, que afirma que a pressão atmosférica diminui com a altitude, e a $h_{2}$, que propõe que o ar exerce pressão sobre a superfície da Terra. No entanto, tal derivação não resolve o problema da contrastação de $h$, pois tanto $h_{1}$ como $h_{2}$ não são diretamente observáveis. Já a proposição de que a altura da coluna de mercúrio contida em um barômetro de Torricelli diminui com o aumento da altitude é uma consequência $t$ da 
hipótese $h_{1}$ que é diretamente contrastável e que, portanto, pode ser defrontada com evidências. Tal exemplo ilustra o primeiro passo do processo de preparação da contrastação de hipóteses que pode ser simbolicamente resumido por $h \rightarrow t$.

Cabe ressaltar, no entanto, que a preparação $h \rightarrow t$ ainda é insuficiente para que a $h$ possa ser contrastada com precisão. Pode ser necessária ainda uma transformação de $t$ em uma linguagem semiempírica, produzindo $t^{*}$. Vejamos o seguinte exemplo: suponhamos que, de uma hipótese aleatória $h$, derivamos a consequência $t$ que diz que um raio de luz deve incidir sobre um plano formando um ângulo $\alpha$ com o mesmo. Os conceitos de raio de luz, plano e ângulo $\alpha$ são todos não empíricos, pois fazem referência a eventos ideais. Não existem feixes de luz que se comportem exatamente como raios de luz; superfícies nunca são perfeitamente planas; e a projeção de uma hipótese nunca nos fornecerá um valor exato para uma grandeza. Em função disso, a contrastação de $t$, que é apresentada em uma linguagem teórica, depende de sua transformação para uma linguagem semiempírica $t^{*}$, ou seja, uma linguagem baseada em conceitos empíricos como, por exemplo: um estreito feixe de luz incide sobre uma superfície formando um ângulo entre $\alpha-\varphi$ e $\alpha+\varphi$ com a mesma, sendo $\varphi$ a incerteza de tal ângulo.

O cerne da transformação $t \rightarrow t^{*}$ não é necessariamente a conversão de conceitos teóricos em conceitos empíricos, mas sim a preparação de proposições diretamente observáveis para serem comparadas com evidências construídas com base em dados coletados experimentalmente. Observemos outro exemplo: $t$ é composta por um conjunto de proposições que determinam a posição de planetas em relação ao Sol em função do tempo. Provavelmente, as evidências construídas por um pesquisador que procura contrastar tais proposições $t$ devem envolver dados das posições dos planetas coletados em relação a um referencial cuja origem se encontra na Terra. Nesse caso, as proposições contidas em $t$ precisam ser convertidas para o mesmo referencial utilizado nas evidências empíricas construídas pelo investigador.

Assim como as proposições que constituem $t$ precisam ser transformadas em $t^{*}$, as evidências $\varepsilon$ coletadas experimentalmente precisam ser preparadas para serem contrastadas com $t^{*}$, produzindo um conjunto de proposições $\varepsilon^{*}$. Esclarecendo tal processo, vamos analisar o seguinte exemplo: um pesquisador deriva de suas hipóteses um conjunto de proposições $t^{*}$ que prediz que a temperatura de um corpo específico decai exponencialmente em função do tempo. $\mathrm{O}$ investigador que procura avaliar seu valor veritativo provavelmente coletará dados da temperatura do corpo em diferentes instantes, e o conjunto desses dados constituirá $\varepsilon$. A fim de preparar $\varepsilon$ para a contrastação com $t^{*}$, o pesquisador poderá ajustar uma curva exponencial aos seus dados $\varepsilon$, que proporcionará um conjunto de predições $\varepsilon^{*}$ diretamente contrastável com $t^{*}$. Será então por meio da confrontação de $\varepsilon^{*}$ e $t^{*}$ que o investigador avaliará se $\varepsilon^{*}$ fornece um apoio empírico ou não para a hipótese $h$.

A Fig. 2 sintetiza a estrutura geral proposta por Bunge para a contrastação de hipóteses e apresenta exemplos para os construtos envolvidos. 


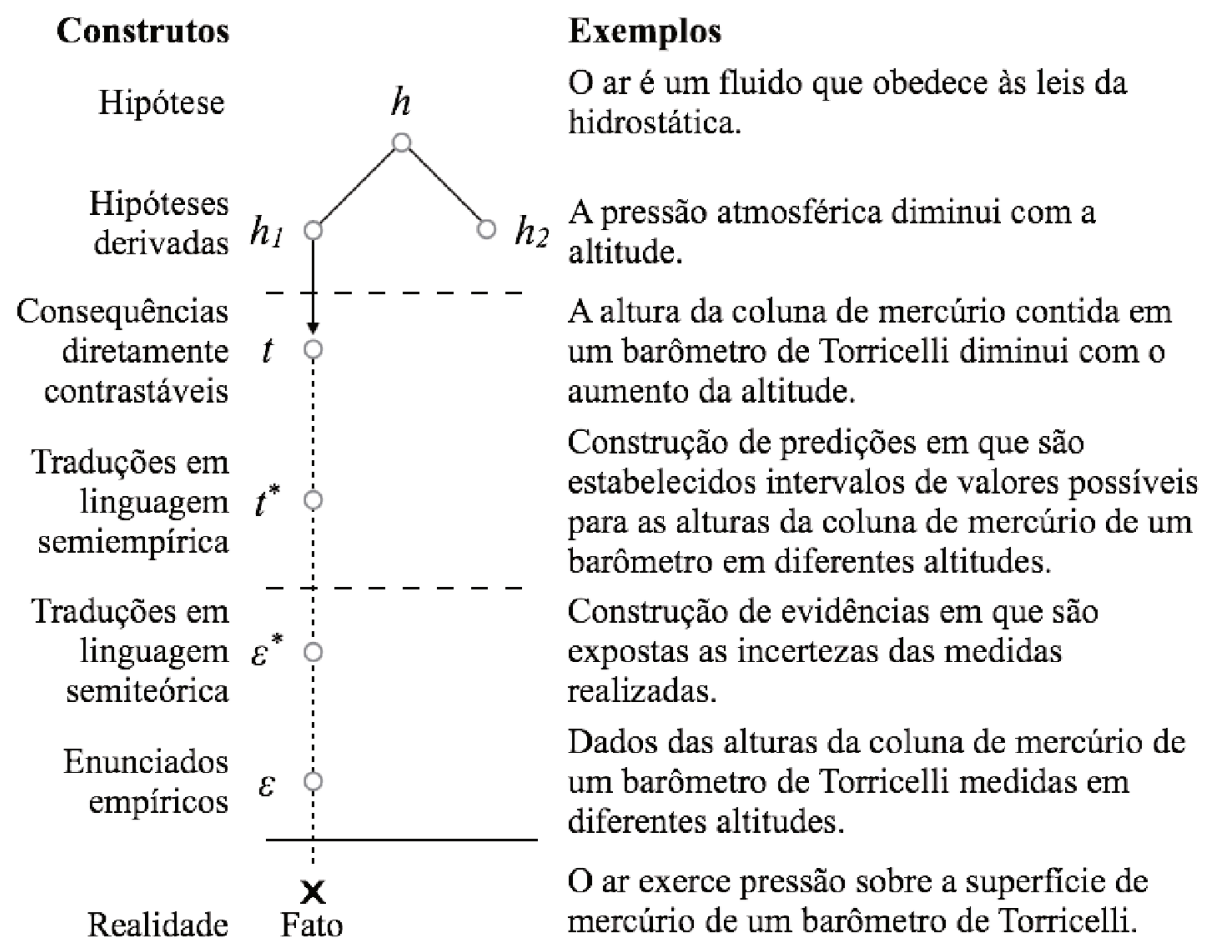

Fig. 2 - As hipóteses científicas não são contrastáveis diretamente. Suas consequências t precisam ser traduzidas para a linguagem semiempirica assim como as evidências $\varepsilon$ precisam ser traduzidas em linguagem semiteórica para finalmente ser possível a contrastação de $t^{*} e \varepsilon^{*}$ (adaptado de BUNGE, 1989, p. 878).

É importante destacar que as evidências das ideias científicas são diferentes das descrições de seus referentes reais. Bunge ressalta tal aspecto exemplificando com a teoria atômica. $\mathrm{O}$ apoio evidencial dessa teoria dificilmente envolverá informações sobre o comportamento individual dos átomos, mas sim sobre fatos molares que implicam em efeitos macroscópicos, como os observados em reações químicas. Dessas evidências são inferidas informações sobre o comportamento dos referentes da teoria atômica, ou seja, dos átomos.

Até o momento, nos concentramos em debater o processo de contrastação das ideias científicas denominadas hipóteses. Passamos agora a apresentar a concepção de Bunge sobre o processo de contrastação das teorias gerais. Ainda que esse processo guarde algumas semelhanças com a contrastação de hipóteses, existem algumas sutilezas que precisam ser ressaltadas quando falamos da avaliação do valor veritativo de teorias.

\section{III.3 Contrastação de teorias científicas}

O que fazemos quando desejamos contrastar uma teoria científica? Corremos para o laboratório imediatamente? Para Bunge, não, pois "há muitas operações conceituais que antecedem as empíricas" (ibid., p. 909). Decorre disso a decisão do autor de distinguir as três 
etapas do processo de contrastação de teorias. São elas: 1) o estágio teórico; 2) o estágio empírico; e 3) a inferência. Na sequência, essas etapas serão debatidas em detalhe.

Segundo Bunge, o estágio teórico é constituído pela organização de cinco elementos básicos para o delineamento de um experimento. São eles: 1a) os pressupostos $P$ da teoria; 1b) os supostos específicos $A$ do modelo teórico que será utilizado; 1c) os dados $\varepsilon_{i}$ de experiências passadas e/ou presentes formulados na linguagem da teoria; 1d) as consequências contrastáveis $t_{i}$; e 1e) interpretação das $t_{i}$ em uma linguagem semiempírica.

Vamos analisar cada um desses elementos por meio de um exemplo: um possível processo de contrastação da mecânica newtoniana. Para isso, imaginemos um indivíduo que procura avaliar o domínio de validade do modelo de pêndulo simples. Mais especificamente, ele busca identificar a amplitude com a qual um pêndulo pode oscilar de modo que seu período não difira de mais de $5 \%$ do valor predito por meio do modelo contrastado.

No exemplo citado, constituem o conjunto $P$ envolvido na contrastação todos os pressupostos da mecânica newtoniana como, por exemplo, a hipótese de proporcionalidade entre o somatório das forças que agem sobre um corpo e a sua aceleração em relação a qualquer referencial inercial. Ainda que esses pressupostos possam ser criticados antes e depois da contrastação empírica, eles não são postos à prova nesse processo, pois a contrastação deles não é direta, mas sim mediada pelo modelo teórico de pêndulo simples. As suposições específicas do modelo de pêndulo simples como, por exemplo, a consideração de que o corpo suspenso é pontual e de que o fio de sustentação é inelástico e desprovido de massa, constituem o conjunto $A$ que dirige a contrastação. Dados de experiências passadas $\varepsilon_{i}$, como, por exemplo, o valor da intensidade do campo gravitacional local, também são necessários para a investigação. Esses dados, em conjunto com os pressupostos $P$ e $A$, possibilitam a dedução de consequências $t_{i}$ da teoria, que constituem o objeto direto da contrastação. No caso da contrastação exemplificada, essa dedução pode resultar no período teórico de pêndulos simples com diferentes comprimentos. Cabe ressaltar que as proposições $t_{i}$ estarão apresentadas com linguagem teórica, pois farão referência direta a conceitos não empíricos estabelecidos dentro do modelo teórico de pêndulo simples. Por isso, Bunge destaca que tais proposições precisam ser interpretadas para uma linguagem semiempírica. Para realizar essa interpretação, usualmente é necessário o uso de uma teoria auxiliar. Por exemplo, no caso exemplificado, o modelo teórico de pêndulo simples prevê valores exatos para o período de pêndulos ideais. Para se contrastar esses períodos, é necessário interpretá-los, com o uso auxiliar de uma teoria de incertezas, para se construir proposições que façam referência a pêndulos reais e que prevejam faixas de intervalo de tempo para os seus períodos, e não valores exatos para os mesmos. Essas interpretações são simbolizadas por Bunge como $t_{i}{ }^{*}$, e o conjunto $\left\{t_{i}{ }^{*}\right\}$ é denominado pelo autor de predições $T^{*}$, ou seja, $\left\{t_{i}^{*}\right\}=T^{*}$. No exemplo analisado, a teoria de incertezas, que é utilizada na confecção das predições contrastáveis, não é posta à prova no processo de contrastação. 
Os elementos que precisam ser organizados no estágio empírico de uma contrastação são, segundo Bunge: 2a) os pressupostos teóricos $Q$ dos procedimentos empíricos; 2b) os enunciados empíricos $\varepsilon_{j}$; e 2c) Interpretação das proposições observacionais com base nos pressupostos $Q$. Vejamos como esses elementos se relacionam com o exemplo que estamos analisando.

O período de um pêndulo não é uma propriedade diretamente observável. Como já foi discutido aqui, precisamos, nesses casos, relacionar uma propriedade observável com a grandeza que se pretende mensurar, e esse processo é mediado por um modelo teórico $Q$. Tomemos como exemplo o caso em que o investigador pretende medir o período de pêndulos reais por meio da mensuração da quantidade de água que escoa pelo orifício de um recipiente durante o intervalo de tempo que se deseja medir, ou seja, por meio de uma clepsidra 6 . A quantidade de água que escoa pelo orifício no instrumento durante um número definido de oscilações de um pêndulo é uma propriedade observável. Podemos inclusive medir essa quantidade coletando-a em um recipiente graduado. No entanto, o tempo transcorrido durante esse escoamento é somente inferido por meio do pressuposto de que esse intervalo é proporcional à quantidade de água que escoou pelo orifício, o que é uma das hipóteses (mais precisamente, uma idealização) que norteiam o modelo teórico $Q$ que ampara o procedimento experimental realizado ${ }^{7}$.

Os enunciados observacionais $\varepsilon_{j}$ da contrastação empírica podem nada mais ser do que dados sobre a altura do nível da água contida no recipiente que coletou a água escoada. Por isso, para torná-los contrastáveis com $T^{*}$, é necessário que seja a interpretação dos $\varepsilon_{j}$ por meio do modelo $Q$, produzindo evidências empíricas $\varepsilon_{j}^{*}$. Por fim, o conjunto $\left\{\varepsilon_{j}^{*}\right\}$ é denominado por Bunge de evidências $E^{*}$, ou seja, $\left\{\varepsilon_{j}^{*}\right\}=E^{*}$. Nesse caso, o modelo $Q$, que é denominado por Bunge de teoria instrumental, precisaria ainda converter a quantidade de água coletada no instrumento para intervalos de tempo, o que possivelmente pode envolver um modelo do tipo caixa preta. É importante perceber que, assim como a teoria auxiliar utilizada na construção de $T^{*}$, o modelo $Q$ não é posto à prova no processo de contrastação.

O último estágio do processo de contrastação de teorias para Bunge é a inferência. Basicamente, tal estágio é definido pela confrontação das predições com as evidências, ou seja, de $T^{*}$ com $E^{*}$. Resultam dessa confrontação dois casos distintos: $\left.3 a\right) E^{*}$ concorda com $T^{*}$; ou 3 b) $E^{*}$ não concorda com $T^{*}$. No primeiro caso, a evidência é compatível com as consequências da teoria considerando os limites aceitáveis das incertezas experimentais. Bunge diz

\footnotetext{
6 As clepsidras foram vastamente utilizadas na história da Ciência por importantes cientistas (MATTEWS, 2000). Galileu Galilei, por exemplo, relacionou o escoamento de água pelo orifício de um recipiente com o intervalo de tempo transcorrido durante o movimento de corpos (SETTLE, 1961).

${ }^{7}$ Evidentemente, o período de um pêndulo pode ser mensurado atualmente com maior precisão e facilidade por meio de fotossensores. Nesse caso, o modelo teórico $Q$, que é implícito para o usuário do instrumento, pois suas medidas são apresentadas automaticamente por meio de displays eletrônicos, envolve desde conhecimentos sobre circuitos elétricos até fundamentos de estado sólido. A escolha por exemplificar o papel do modelo $Q$ com o uso da clepsidra foi para tornar a compreensão das ideias de Bunge mais simples, pois, no caso da clepsidra, o modelo $Q$ é explícito e mais trivial do que no caso de um fotossensor.
} 
então que a contrastação fornece apoio empírico à teoria contrastada, não uma prova da mesma. Quando $E^{*}$ não concorda com $T^{*}$, ou seja, quando a discordância entre as predições e os dados ultrapassa a margem de tolerância da contrastação, duas são as possibilidades: as evidências discrepantes ou são aceitas como verdadeiras ou rejeitadas como suspeitas. A decisão por uma dessas opções depende da análise criteriosa das operações empíricas realizadas na coleta dos enunciados observacionais $\varepsilon$ e da possível avaliação desses enunciados dentro de outros corpos de conhecimento distintos dos que foram utilizados na investigação.

As considerações de Bunge sobre o fazer experimental e sobre a contrastação de teorias evidenciam que a visão ingênua de que teorias e experiência são diretamente contrastáveis é insuficiente. Além disso, a concepção frequentemente identificada no meio acadêmico de que as predições são decorrentes exclusivamente das teorias e de que os dados brutos, que são contrastáveis com essas predições, são coletados diretamente da experiência, é também incompleta. $\mathrm{O}$ autor destaca que as predições e as evidências são construídas com o auxílio de teorias auxiliares e de dados de experiências anteriores. A Fig. 3 sintetiza essas concepções.

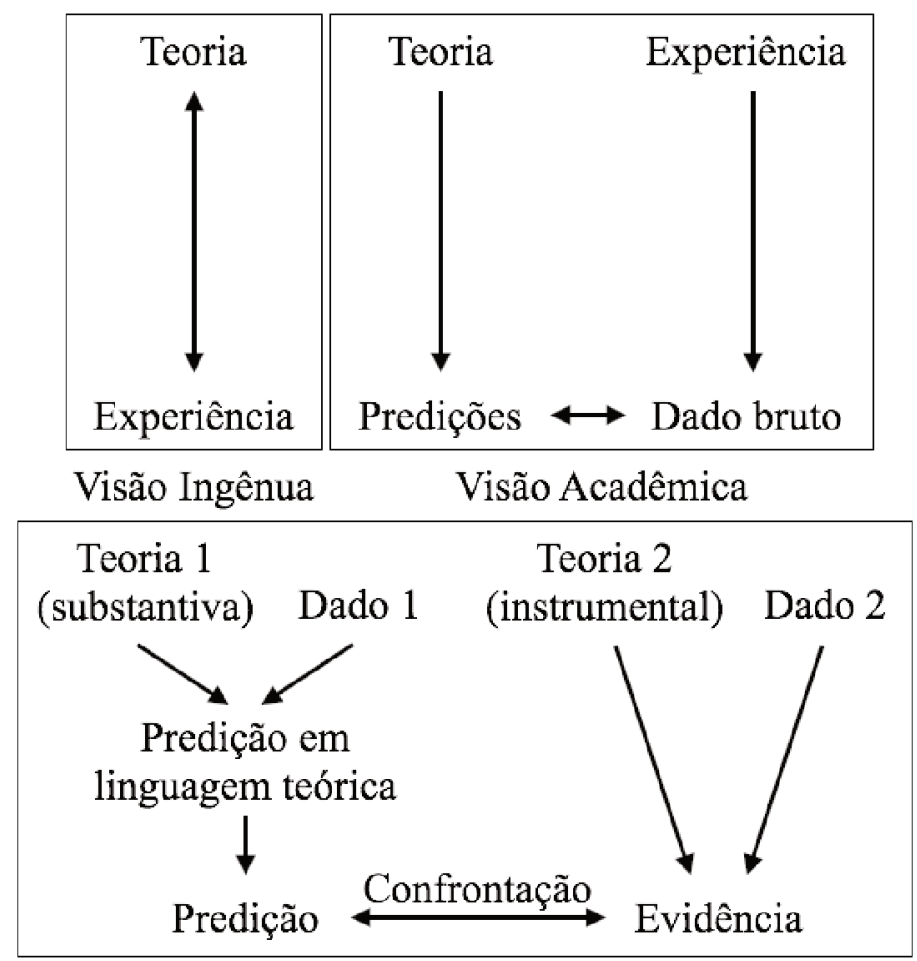

Procedimento Real

Fig. 3 - Contrastação de teorias: na visão ingênua, teoria e experiência são contrastadas diretamente; a visão acadêmica entende que as predições derivam diretamente das teorias; o procedimento real envolve o uso de teorias auxiliares (BUNGE, 1989, p. 540).

Na Fig. 4 relacionamos o esquema proposto por Bunge para representar o procedimento de contrastação de teorias científicas com os exemplos apresentados nesta seção. 
Evidenciamos nesta seção que Bunge entende que o estágio teórico antecede o empírico no processo de contrastação das ideias científicas. Isso porque o delineamento das operações empíricas é fortemente influenciado pelos pressupostos teóricos em confrontação. Além disso, a construção de predições e de evidências envolve o uso de teorias auxiliares que nem mesmo são postas à prova nas investigações. Fica evidente, portanto, que o trabalho experimental é sempre delineado, conduzido e avaliado dentro de um corpo teórico composto por teorias, modelos, hipóteses, etc.

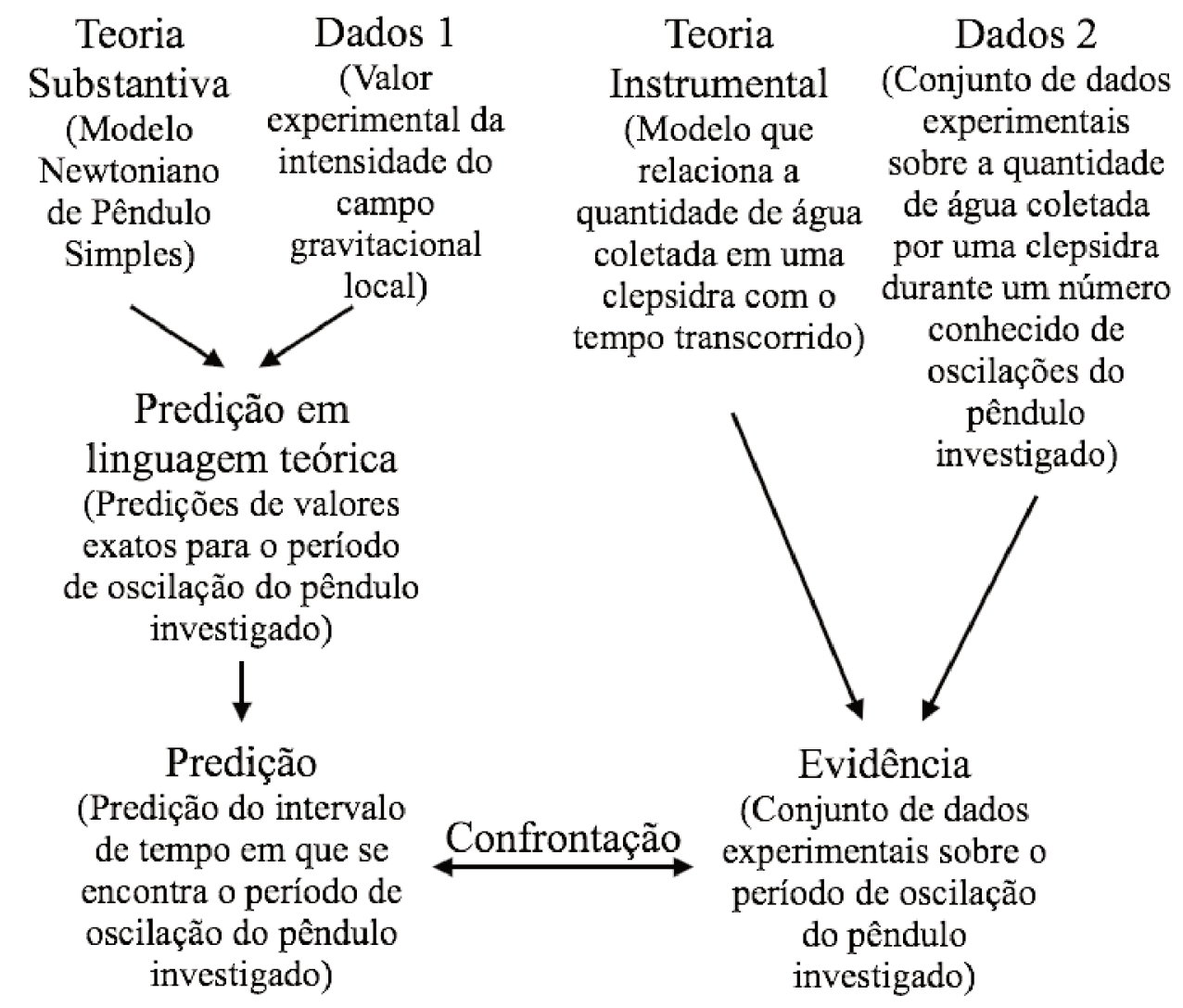

Fig. 4 - Exemplo de contrastação empírica de uma teoria científica. O modelo newtoniano de pêndulo simples é usado na avaliação da Mecânica Newtoniana, que é o alvo mediato da contrastação (adaptado de BUNGE, 1989, p. 540).

Na próxima seção, baseados na concepção bungeana sobre a contrastação empírica das ideias científicas, propomos uma expansão do campo conceitual da modelagem didáticocientífica de Brandão, Araujo e Veit (2012), incorporando conceitos, teoremas e situações especificamente relacionados com o trabalho experimental. 


\section{O trabalho experimental no campo conceitual da modelagem didático-científica}

Baseados nos debates de Bunge sobre o processo de contrastação das ideias científicas, ampliamos a Estrutura Conceitual de Referência (ECR) do campo conceitual da modelagem didático-científica (apresentada na Fig. 1) incluindo os principais conceitos e relações específicos do trabalho empírico, conforme apresentado na Fig. 5. Com o objetivo de torná-la mais sintética, a estrutura original proposta por Brandão, Araujo e Veit é subsumida no quadro "Modelagem Didático-Científica". Os conceitos que tangenciam tal quadro devem ser entendidos como conceitos interligados por meio da estrutura original.

$\mathrm{Na}$ ECR exposta na Fig. 5, é destacado que o delineamento investigativo de uma prática experimental realizada para se responder uma questão de pesquisa é dirigido por um modelo teórico de referência. Esse modelo subsidia o pesquisador com conhecimentos que o auxiliam para, entre outras coisas, definir as grandezas de interesse do estudo, identificar os fatores que influenciam essas grandezas, assim como para delinear os procedimentos que serão realizados na análise dos dados empíricos coletados na investigação. Portanto, em acordo com as ideias de Bunge, partimos, na construção da ECR, do pressuposto que as investigações empíricas são delineadas apoiadas em corpos teóricos pré-estabelecidos.

$\mathrm{O}$ delineamento de uma investigação experimental envolve o planejamento de uma ou mais operações empíricas, que, segundo Bunge, são de três tipos: observações, medições e experimentos. Na ECR, é ressaltado que as operações empíricas são amparadas em um modelo teórico de referência auxiliar. Por exemplo, para se medir uma grandeza inobservável, podemos usar um modelo teórico que relaciona essa grandeza com uma propriedade observável. Um exemplo disso é demonstrado no caso da clepsidra, abordado na Seção III.1, em que o tempo, que é uma propriedade inobservável, é vinculado por um modelo teórico com a quantidade de água que escorre por um orifício, que é uma grandeza observável. É interessante ressaltar que os modelos teóricos auxiliares utilizados em uma operação empírica não são, $a$ priori, postos à prova nas investigações experimentais. Além disso, devemos destacar que o modelo teórico que dirige o delineamento investigativo pode ser completamente distinto dos modelos que amparam as operações empíricas abrangidas em uma investigação. Por exemplo, o modelo teórico que norteou os estudos de Galileu quando ele estudou o movimento de corpos em planos inclinados era completamente distinto do modelo que amparava o funcionamento das clepsidras usadas por ele (SETTLE, 1961).

Ainda sobre as operações empíricas, é ressaltado na ECR da Fig. 5 que os experimentos pressupõem o controle de variáveis. Tal procedimento é realizado por dois motivos: i) para se controlar nos experimentos os fatores que são desprezados nos modelos teóricos de referência das investigações empíricas, justificando a conexão entre idealizações/aproximações e controle de variáveis sugerida na Fig. 5, ii) para garantir que os efeitos de uma causa produzidos em um experimento sejam decorrentes apenas dessa causa, e não de mudanças em variáveis não controladas no evento explorado. Dependendo, por exemplo, da relação entre grandezas que se deseja testar no experimento, diferentes variáveis precisarão 
ser controladas e/ou alteradas, justificando assim a conexão entre questão de pesquisa e controle de variáveis proposta na ECR.

Na Fig. 5 procuramos destacar também que, como foi debatido na Seção III.1, os dados empíricos coletados em uma investigação não são diretamente contrastáveis. Eles precisam primeiramente ser traduzidos em linguagem semiteórica para produzir evidências, que muitas vezes não são proposições diretas sobre o comportamento dos referentes do modelo teórico que dirige a investigação. Evidências relacionadas ao comportamento de átomos, por exemplo, normalmente envolvem proposições empíricas relacionadas ao comportamento molar de substâncias. Além disso, ressaltamos na ECR que as predições geradas em uma investigação não são derivadas exclusivamente do seu modelo teórico de referência. Antes disso, é necessário se produzir dados contrastáveis por meio de uma combinação entre esse modelo e dados empíricos previamente conhecidos sobre o sistema investigado. Por exemplo, para se predizer o período de um pêndulo utilizando o modelo de pêndulo simples, é necessário se conhecer previamente a intensidade do campo gravitacional local e o comprimento do fio de sustentação do pêndulo, dados esses empíricos, não postos à prova na investigação. Os dados contrastáveis produzidos precisam ainda ser traduzidos em linguagem semiempírica para produzirem predições que podem ser confrontadas com as evidências, possibilitando a contrastação empírica. Essa confrontação pode elucidar o domínio de validade e o grau de precisão do modelo teórico de referência da investigação, alvo imediato da contrastação empírica. As teorias gerais e as hipóteses são apenas mediatamente testadas em uma pesquisa empírica, pois, por natureza, elas não se pronunciam sobre eventos específicos.

Identificamos associações entre os conceitos da ECR da MDC apresentada na Fig. 1 e os conceitos inseridos com a incorporação do fazer experimental (Fig. 5) por meio dos teoremas-em-ação. Por exemplo, associado ao conceito de controle de variáveis, identificamos o invariante operatório "Estabelecer procedimentos de controle de variáveis que minimizem a influência dos fatores desprezados no modelo teórico de referência da investigação". Como os fatores desprezados em um modelo dependem diretamente das simplificações da realidade consideradas, o conceito de controle de variáveis pode ser associado ao conceito de idealização. No Quadro 1 sintetizamos as associações identificadas entre os vários conceitos.

Quadro 1 - Associação entre conceitos específicos do trabalho empírico (Fig. 5) com os conceitos da ECR construída por Brandão, Araujo e Veit (2011) - (BAV).

\begin{tabular}{|l|l|}
\hline Conceitos identificados em BAV & $\begin{array}{l}\text { Conceitos específicos associados trabalho } \\
\text { empírico }\end{array}$ \\
\hline Modelos e modelagem & Delineamento experimental \\
\hline Referente & Evidência \\
\hline Idealização e aproximação & Controle de variáveis \\
\hline Variáveis e parâmetros & Operação empírica, predição e evidência \\
\hline $\begin{array}{l}\text { Domínio de validade, grau de precisão, ex- } \\
\text { pansão e generalização }\end{array}$ & Contrastação empírica \\
\hline
\end{tabular}




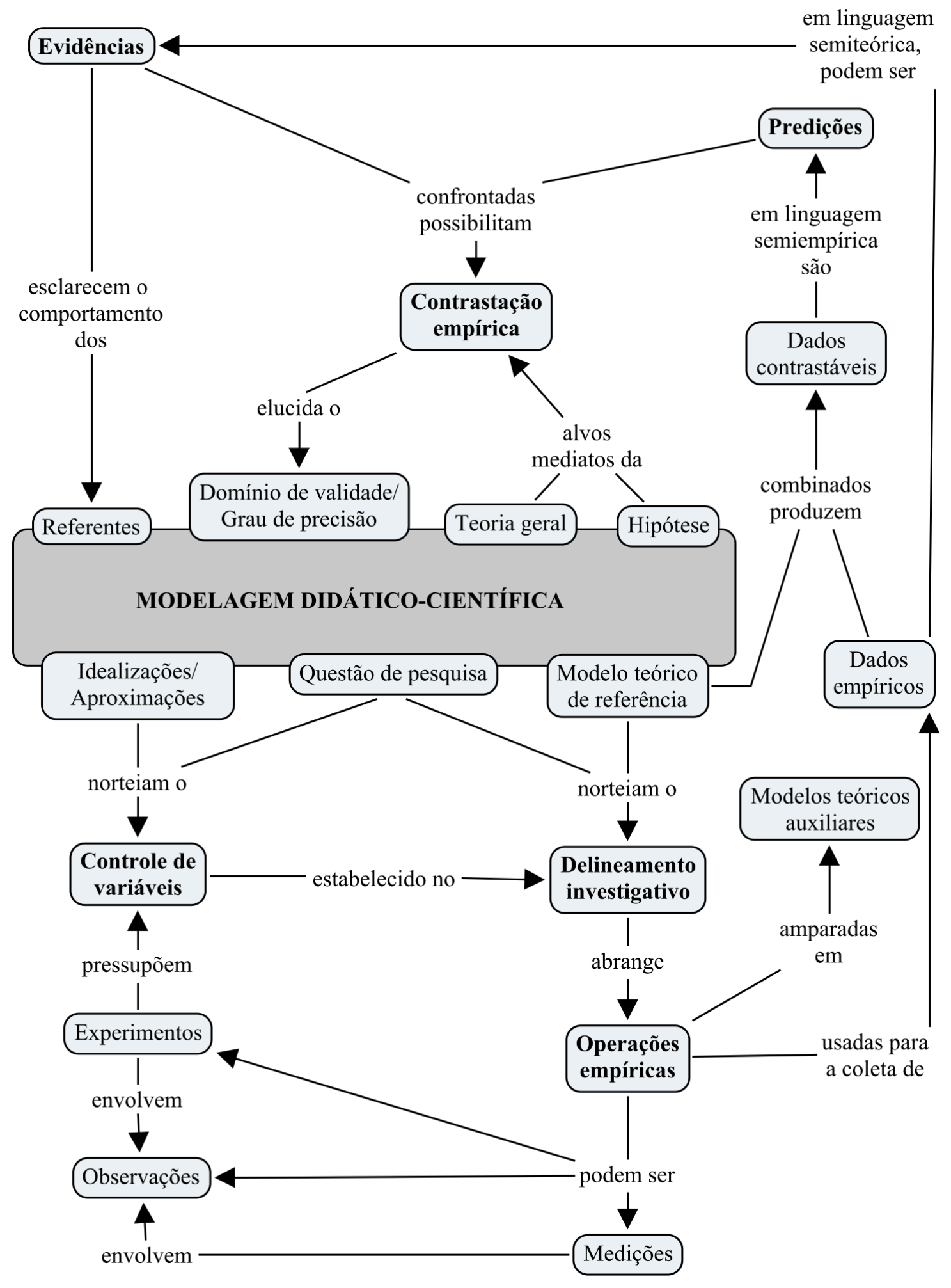

Fig. 5 - Estrutura conceitual de referência do processo de contrastação empírica das ideias científicas vinculada a processo de modelagem científica. Os conceitos que tangenciam o quadro "modelagem didático-científica" devem ser entendidos como conceitos interligados por meio da estrutura apresentada na Fig. 1. 
Apresentamos no Quadro 2 doze invariantes operatórios de referência para os conceitos associados ao trabalho empírico (coluna da direita do Quadro 1). Brandão, Araujo e Veit (2011) apresentaram treze invariantes operatórios de referência associados aos conceitos apresentados na coluna da esquerda do Quadro 1.

Quadro 2 - Invariantes Operatórios de Referência do campo conceitual da modelagem didático-científica especificamente vinculados com o trabalho experimental.

\begin{tabular}{|c|c|}
\hline \multirow{3}{*}{$\begin{array}{l}\text { Delineamento } \\
\text { experimental }\end{array}$} & $\begin{array}{l}\text { Formular questões sobre uma situação física a serem respondidas por } \\
\text { meio do uso de modelo(s) científico(s) em uma investigação empírica. }\end{array}$ \\
\hline & $\begin{array}{l}\text { Escolher o modelo científico que amparará o delineamento e a interpreta- } \\
\text { ção da investigação empírica, ou seja, escolher um modelo teórico de re- } \\
\text { ferência. }\end{array}$ \\
\hline & $\begin{array}{l}\text { Delinear um arranjo experimental baseado no modelo teórico de referên- } \\
\text { cia para utilizar na investigação empírica. }\end{array}$ \\
\hline Evidências & $\begin{array}{l}\text { Estabelecer relações entre dados empíricos e o comportamento dos refe- } \\
\text { rentes do modelo teórico de referência da investigação. }\end{array}$ \\
\hline $\begin{array}{l}\text { Controles de } \\
\text { variáveis }\end{array}$ & $\begin{array}{l}\text { Estabelecer procedimentos de controle de variáveis que minimizem a in- } \\
\text { fluência dos fatores desprezados no modelo teórico de referência da in- } \\
\text { vestigação. }\end{array}$ \\
\hline $\begin{array}{l}\text { Operação empí- } \\
\text { rica }\end{array}$ & $\begin{array}{l}\text { Definidas as grandezas que necessitam ser conhecidas em uma investiga- } \\
\text { ção, delinear operações empíricas para a coleta de dados empíricos perti- } \\
\text { nentes para a pesquisa. }\end{array}$ \\
\hline Evidência & $\begin{array}{l}\text { Coletado um conjunto de dados empíricos brutos, realizar a(s) transfor- } \\
\text { mação(ões) necessária(s) para torná-los contrastáveis com predições. }\end{array}$ \\
\hline Predição & $\begin{array}{l}\text { Baseado em hipóteses e/ou no modelo teórico de referência da investiga- } \\
\text { ção, e em dados conhecidos sobre o evento físico investigado, predizer o } \\
\text { comportamento das grandezas pertinentes para a investigação realizada. }\end{array}$ \\
\hline \multirow{4}{*}{$\begin{array}{l}\text { Contrastação } \\
\text { empírica }\end{array}$} & $\begin{array}{l}\text { Confrontar as predições com as evidências da investigação avaliando se } \\
\text { as evidências construídas fornecem um apoio empírico à teoria geral con- } \\
\text { trastada ou se a discordância entre predições e evidências supera a tole- } \\
\text { rância aceitável para a investigação. }\end{array}$ \\
\hline & $\begin{array}{l}\text { Avaliar o domínio de validade e o grau de precisão do modelo teórico de } \\
\text { referência da investigação, confrontando as predições obtidas com esse } \\
\text { modelo e as evidências construídas na pesquisa. }\end{array}$ \\
\hline & $\begin{array}{l}\text { Realizada a confrontação entre as predições e as evidências, avaliar a ne- } \\
\text { cessidade de se expandir o modelo teórico de referência da investigação. }\end{array}$ \\
\hline & $\begin{array}{l}\text { Realizada a confrontação entre as predições e as evidências, verificar se o } \\
\text { modelo teórico de referência da investigação pode ser útil para representar } \\
\text { outros sistemas físicos distintos daquele com o qual ele foi contrastado. }\end{array}$ \\
\hline
\end{tabular}

Precisamos ressaltar aqui que nosso foco na contrastação de ideias científicas está voltado para as situações enfrentadas pelos estudantes em atividades didáticas de laboratório. 
Nossa aspiração é que o sentido atribuído aos conceitos tratados na ECR da Figura 5 seja gradativamente construído pelos alunos à medida que se defrontam com situações-problema cujas soluções necessitem de esquemas de ação que envolvam esses conceitos. Cabe ao professor planejar situações-problema adequadas para promover esse processo.

Na próxima seção, ilustramos como a Modelagem Didático-Científica, cuja expansão foi discutida, pode dar suporte a uma atividade de cunho experimental envolvendo o modelo de sistema massa-mola amortecido. Exemplificamos eventos em que os estudantes precisam mobilizar alguns dos invariantes operatórios apresentados no Quadro 2, assim como situações que têm potencial para dar sentido aos conceitos do campo conceitual da modelagem didáticocientífica especificamente relacionados com o fazer experimental.

\section{Análises de uma atividade experimental à luz da MDC}

Um dos princípios mais importantes da MDC é herdado da Teoria dos Campos Conceituais de Vergnaud: as situações dão sentido aos conceitos. Em função disso, nosso ponto de partida para o delineamento e a condução de atividades experimentais amparadas na MDC é a escolha de situações que podem dar sentido aos conceitos do campo conceitual da modelagem didático-científica, ou seja, que demandem a mobilização de esquemas de ação que envolvam conceitos e teoremas associados com o processo de modelagem de um problema de Física.

Outro princípio básico da MDC, herdado da concepção de Bunge sobre modelagem científica, é que conhecemos a realidade por meio da construção de representações parciais e imperfeitas. Essa é a pedra angular para a compreensão do vínculo entre teoria e prática, que será ilustrado nessa seção com uma atividade experimental sobre o movimento amortecido de um corpo. Em particular, discutimos conceitos-em-ação e teoremas-em-ação que precisam ser mobilizados pelos estudantes desde que sejam instigados a refletirem e tomarem decisões em suas investigações. Enfatizamos os invariantes operatórios de referência associados ao trabalho experimental identificados no Quadro 2, pois a originalidade do presente artigo se relaciona ao fazer experimental.

Optamos por ilustrar com uma atividade sobre movimento amortecido porque é um experimento consagrado nas disciplinas experimentais que abordam mecânica. No guia da atividade, voltado para estudantes de graduação em Física e disponibilizado em Heidemann, Araujo e Veit (2015), tomamos o cuidado para não dirigirmos os estudantes excessivamente, dando oportunidade para que eles tomem decisões em suas investigações. Não detalharemos aqui a problematização da atividade, que envolve indagações sobre sistemas de amortecimento automotivos e pode ser consultada em Heidemann, Araujo e Veit (2015; 2016). Com o objetivo de enfocar nessa seção nos conhecimentos que os estudantes precisam mobilizar em investigações experimentais, partimos das questões que os dirigem especificamente durante o delineamento, a condução e a análise de suas operações empíricas. São elas: 
Quais os principais fatores que influenciam no amortecimento da oscilação de um corpo suspenso por uma mola que se move imerso em um fluido? Como esses fatores influenciam na oscilação desse corpo? Do que dependem esses fatores?

Espera-se que, a partir de uma exposição dialogada conduzida pelo professor, os estudantes concluam que o movimento de um corpo suspenso por uma mola que se move imerso em um fluido pode ser representado por um modelo teórico construído com base no objetomodelo de sistema massa-mola amortecido e na mecânica newtoniana, que denominamos aqui apenas como modelo de sistema massa-mola amortecido ${ }^{8}$. Desse modo, o objetivo geral dos estudantes na atividade é avaliar a adequação desse modelo para representar o movimento de corpos que oscilam suspensos por molas e imersos em fluidos. Não se espera que os estudantes avaliem a influência de todos os parâmetros e variáveis envolvidas no modelo de sistema massa-mola amortecido no movimento de sistemas reais. Deseja-se que investiguem ao menos a influência de uma característica do sistema, como a constante elástica da mola de sustentação ou da massa do corpo que oscila, por exemplo.

Qualquer que seja a questão que os estudantes se proponham a responder, quando planejam e executam seus experimentos, serão requeridos conceitos-em-ação como os de controle de variáveis, predições, evidências, domínio de validade, grau de precisão, idealização e aproximação, assim como os correspondentes teoremas-em-ação apresentados no Quadro 2. No que segue, ilustraremos eventos em que esses conceitos e os teoremas-em-ação são mobilizados pelos estudantes em suas investigações.

Para delinearem as investigações que desenvolverão, os estudantes necessitam realizar uma série de ações. Uma delas é a definição de uma questão de pesquisa. Dependendo do enfoque das suas investigações, os estudantes podem optar por avaliar a influência de diferentes fatores no amortecimento do corpo oscilante, implicando em diferentes questões de pesquisa. Para estabelecer uma questão de pesquisa precisa e condizente com os seus objetivos, precisam formulá-la baseados em um modelo teórico de referência. Desse modo, precisam mobilizar um esquema de ação que envolve o uso do seguinte invariante operatório: Formular questões sobre uma situação física a serem respondidas por meio do uso de modelo(s) científico(s) em uma investigação empírica.

Outra ação dos estudantes relacionada com o planejamento das suas investigações é o delineamento de um arranjo experimental. Como foi destacado na Seção III.1, o controle de variáveis é um aspecto central de um experimento e ele deve ser previsto nesse arranjo. Por exemplo, como o modelo de sistema massa-mola amortecido pressupõe que a mola de sustentação tem massa desprezível, é importante que o estudante preveja o uso de molas com massas muito pequenas quando comparadas com as massas dos corpos suspensos. Desse modo, ele estará controlando a influência da massa da mola sobre o movimento do corpo suspenso. Fica claro, portanto, que, nesse processo, é preciso mobilizar os seguintes invariantes operató-

\footnotetext{
8 A histórica denominação de "sistema massa-mola" pode confundir o aluno, pois nomeia um dos corpos (o que oscila preso à mola) por uma propriedade sua (a massa).
} 
rios: i) Delinear um arranjo experimental baseado no modelo teórico de referência para utilizar na investigação empírica e ii) Estabelecer procedimentos de controle de variáveis que minimizem a influência dos fatores desprezados no modelo teórico de referência da investigação.

A realização desse procedimento dá oportunidade para que compreendam o caráter representacional dos modelos científicos, o que é um dos objetivos gerais de aprendizagem da atividade. $\mathrm{O}$ modelo de sistema massa-mola amortecido toma por base um sistema idealizado, que consiste em um corpo rígido, que contém toda a massa do sistema, suspenso por uma mola de massa desprezível, responsável por toda a elasticidade do sistema, oscilando em um plano vertical em torno de uma posição de equilíbrio. Estando o corpo imerso em um fluido, o seu amortecimento depende da força de arrasto sofrida, que pode ser considerada proporcional à sua velocidade a menos de uma constante que depende de características do fluido e do corpo (por exemplo, densidade e viscosidade do fluido, forma e superfície do corpo). Desse modo, a atividade defronta os estudantes com questões que evidenciam que existem condições que precisam ser aproximadamente respeitadas para que o modelo para o sistema massa-mola amortecido produza resultados com o grau de precisão desejado.

Um aspecto central do delineamento das investigações dos estudantes é a definição das operações empíricas que serão realizadas. Centrados nas questões de pesquisa, é necessário, por exemplo, que definam as grandezas que precisam ser mensuradas e os instrumentos que serão utilizados em suas medidas. Por exemplo, para medirem a posição do corpo oscilante investigado em função do tempo, os estudantes podem optar por realizar uma videoanálise do movimento do corpo sob investigação com algum software (por ex., o Tracker $^{9}$ ). Para realizarem essa escolha, eles mobilizam o seguinte invariante operatório: Definidas as grandezas que necessitam ser conhecidas em uma investigação, delinear operações empíricas para a coleta de dados empíricos pertinentes para a pesquisa.

Durante a condução das suas investigações, os estudantes necessitam construir predições e evidências. Para as predições, além de se ampararem no modelo de sistema massamola amortecido, precisam coletar dados sobre o evento que investigarão. Por exemplo, o conhecimento da constante elástica da mola de sustentação é imprescindível para que os estudantes possam construir predições dos períodos de oscilação dos sistemas reais investigados com base no modelo de sistema massa-mola amortecido. Por isso, para construírem predições, os estudantes mobilizam o seguinte invariante operatório: Baseado no modelo teórico de referência da investigação e em dados conhecidos sobre o evento físico investigado, predizer o comportamento das grandezas pertinentes para a investigação realizada.

Por outro lado, a construção de evidências demanda a transformação dos dados experimentais para torná-las contrastáveis com as predições. Por exemplo, suponhamos que os estudantes desejam contrastar predições do período de oscilação de um corpo que oscila imer-

9 O software Tracker é disponibilizado gratuitamente em: <http://physlets.org/tracker/>. Acesso em: 01 set. 2015. 
so em um fluido suspenso por uma mola. Se eles coletaram seus dados por meio de uma videoanálise com um software, obtendo um conjunto de dados referentes à posição em função do tempo do corpo investigado, eles precisam inferir o período de oscilação desse corpo para construírem evidências contrastáveis com suas predições, ou seja, precisam realizar uma transformação dos dados experimentais. Desse modo, mobilizam o seguinte invariante operatório: Coletado um conjunto de dados empíricos brutos, realizar a(s) transformação(ões) necessária(s) para torná-los contrastáveis com predições.

Ao final das suas investigações, espera-se que os estudantes tenham condições de avaliar o domínio de validade do modelo de sistema massa-mola amortecido. Para isso, precisam contrastar predições e evidências levando em consideração as incertezas desses dados. Desse modo, mobilizam esquemas de ação que envolvem o seguinte invariante operatório: Avaliar o domínio de validade e o grau de precisão do modelo teórico de referência da investigação, confrontando as predições obtidas com esse modelo e as evidências construídas na pesquisa.

Cabe observar que nosso objetivo nessa seção foi o de ilustrar alguns dos conhecimentos apresentados no Quadro 2 que podem ser mobilizados pelos estudantes em uma atividade experimental, exemplificando também algumas situações com potencial para dar sentido àqueles conceitos. Destacamos os invariantes operatórios relacionados ao fazer experimental, mas conhecimentos de caráter mais geral também estão envolvidos.

Mais detalhes sobre esta e outras atividades desenvolvidas com base na MDC, incluindo guias para a implementação em aulas de laboratório, podem ser consultados em Heidemann (2015) e Heidemann, Araujo e Veit (2015; 2016). Nessas referências também é aprofundado o debate sobre a necessidade de atividades experimentais que favoreçam a compreensão da vinculação entre teoria e prática. É apresentada também uma proposta metodológica, denominada de Episódios de Modelagem, para se conduzir atividades experimentais em nível de Física Geral que promovam tal vinculação.

\section{Considerações finais}

Diversos autores têm destacado limitações das atividades experimentais tradicionalmente conduzidas no ensino de Ciências (HODSON, 1994; BORGES, 2002; TRUMPER, 2003; CARVALHO, 2010), justificando a necessidade de reflexões sobre novas alternativas teóricas e metodológicas para o delineamento e a realização dessas atividades. Nesse cenário, a MDC surge como uma construção teórica que pode alicerçar essas reflexões, promovendo um aprofundamento sobre a compreensão dos processos cognitivos exigidos dos estudantes quando enfrentam situações que demandam a construção, a exploração e/ou a validação de modelos teóricos da Física, especialmente em atividades experimentais. Com isso, é possível se delinear e avaliar com maior clareza atividades que defrontem os estudantes com situações propícias para que ampliem seus domínios sobre o campo conceitual da modelagem didáticocientífica e, progressivamente, se tornem mais competentes para mobilizar os conhecimentos 
predicativos abordados nas aulas de Física para construir representações de eventos reais, ou seja, de eventos que abarcam toda a complexidade da realidade. Desse modo, os estudantes podem superar a crença de que os conceitos científicos só são empregáveis na resolução de problemas acadêmicos previamente idealizados. Entende-se ainda que, a partir da compreensão de que teorias e realidade são mediadas por modelos científicos, os estudantes podem entender o papel dos modelos no processo de apreensão da realidade em situações que envolvem a representação de eventos reais, aproximando teoria e prática nas aulas de Física.

Diversos também são os autores que propõem referenciais teóricos que implicam um ensino de Física voltado para investigações, que estimulam uma postura crítica por parte dos estudantes frente às possíveis soluções existentes para os problemas abordados. Carvalho (2013), por exemplo, apresenta a proposta de "Sequência de Ensino Investigativo" argumentando que os problemas propostos aos estudantes precisam levá-los a questionar seus conhecimentos prévios, possibilitando a construção de conhecimentos novos. No entanto, mesmo reconhecendo os méritos dessas propostas, entendemos que a MDC contribui para a área de ensino de Física por ser um referencial bem amparado teórica e epistemologicamente que elucida parte dos conhecimentos requeridos no enfrentamento de situações em que os estudantes precisam construir representações simplificadas com o objetivo de resolver um problema sobre a realidade.

Com ela, é possível se avançar nas investigações da área que procuram identificar os esquemas de ação utilizados pelos estudantes em situações que envolvem o uso, a exploração e a validação de modelos científicos. Resultados de estudos empíricos presentes em Heidemann (2015) e em Heidemann, Araujo e Veit (2013) demonstram, por exemplo, que atividades experimentais com enfoque no processo de modelagem científica têm potencial para possibilitar que os estudantes ampliem seus domínios sobre o campo conceitual da modelagem didático-científica, especialmente no que se refere à compreensão sobre o papel dos modelos científicos no delineamento, na realização e na análise de experimentos. Cabe destacar, no entanto, que ainda que Brandão (2012) e Brandão, Araujo e Veit (2014) tenham identificado alguns invariantes operatórios utilizados por estudantes em situações de modelagem, há ainda muito que se fazer neste sentido. Estudos com o objetivo de identificar invariantes operatórios do campo conceitual da modelagem didático-científica especialmente associados com o trabalho experimental acionados pelos estudantes em atividades experimentais com enfoque no processo de modelagem científica estão entre a perspectivas de trabalho dos autores deste artigo.

\section{Agradecimentos}

Agradecemos aos avaliadores do presente artigo pelos comentários e sugestões que contribuíram para o enriquecimento e maior clareza ao texto. Agradecemos também ao professor Fernando Lang da Silveira pelos debates que possibilitaram um aprofundamento sobre os fundamentos teóricos deste artigo. 


\section{Referências bibliográficas}

BORGES, A. T. Novos rumos para o laboratório escolar de ciências. Caderno Brasileiro de Ensino de Física, Florianópolis, v. 24, p. 9-30, 2002. ed. especial.

BOULTER, C. J.; GILBERT, J. K. Challenges and opportunities of developing models in science education. In: . (Org.). Developing models in science education, New York: Kluwer Academic Publishers, 2000, p. 343-362.

BRANDÃO, R. V. A estratégia da modelagem didático-científica reflexiva para a conceitualização do real no ensino de Física. 2012. 230 f. Tese (Doutorado em Ensino de Física) Instituto de Física, Universidade Federal do Rio Grande do Sul, Porto Alegre.

BRANDÃO, R. V.; ARAUJO, I. S.; VEIT, E. A. A modelagem científica de fenômenos físicos e o ensino de física. A Física na Escola, São Paulo, v. 9, n. 1, p. 10-14, maio 2008.

- A modelagem científica vista como um campo conceitual. Caderno Brasileiro de Ensino de Física, Florianópolis, v. 28, n. 3, p. 507-545, dez. 2011.

Scientific modeling seen as a conceptual field: theoretical approach and preliminary empirical evidences of possible operational invariants on the learning of physics. In: The World Conference on Physics Education, 2012, Instambul. WCPE - Book of Abstracts. Instambul: Bahesehir Universitesi, 2012. v. 1. p. 273-282.

. Um estudo de caso para dar sentido à tese de que a modelagem científica pode ser vista como um campo conceitual. Revista Electrónica de Investigación en Educación en Ciencias, Tandil, v. 9, n. 1, p. 1-21, julio 2014.

BUNGE, M. Teoria e realidade. São Paulo: Editora Perspectiva, 1974.

. Epistemologia: Curso de atualização. São Paulo: Editora da USP, 1980.

La investigación científica: Su estrategia e su filosofía. Barcelona: Editora Ariel, 1989.

La Ciencia: Su método y su filosofía. Buenos Aires: Editorial Sudamericana, 1998.

. Caçando a realidade. São Paulo: Editora Perspectiva, 2010.

; ARDILA, R. Filosofía de la psicología. Buenos Aires: Siglo XXI Editores, 2002.

CARVAlHO, A. M. P. As práticas experimentais no ensino de Física. In: (Org.). Ensino de Física. São Paulo: Cengage Learning, 2010. p. 53-78. 
CARVALHO, A. M. P. Ensino de Ciências por investigação: Condições para implementação em sala de aula. São Paulo: Cengage Learning, 2013.

CUPANI, A.; PIETROCOLA, M. A relevância da epistemologia de Mario Bunge para o ensino de ciências. Caderno Brasileiro de Ensino de Física, Florianópolis, v. 19, n. Especial, p. 100-125, jun. 2002.

HEIDEMANN, L. A. Ressignificação da atividades experimentais no ensino de Física por meio do enfoque no processo de modelagem científica. 2015. 298 f. Tese (Doutorado em Ensino de Física) - Instituto de Física, Universidade Federal do Rio Grande do Sul, Porto Alegre.

HEIDEMANN, L. A.; ARAUJO, I. S.; VEIT, E. A. Ciclos de Modelagem: uma alternativa para integrar atividades baseadas em simulações computacionais e atividades experimentais no ensino de Física. Caderno Brasileiro de Ensino de Física, Florianópolis, v. 29, n. Especial 2, p. 965-1007, out. 2012.

- Um estudo exploratórios sobre atividades experimentais para graduandos de Física focadas no processo de modelagem científica. In: IX CONGRESO INTERNACIONAL SOBRE INVESTIGACIÓN EN DIDÁCTICA DE LAS CIENCIAS, 2013, Girona. Enseñanza de las Ciencias. Barcelona: 2013.

Atividades experimentais com enfoque no processo de modelagem científica: uma alternativa para a ressignificação das aulas de laboratório em cursos de graduação em física. Revista Brasileira de Ensino de Física, São Paulo, v. 38, n. 1, p. 1504-1515, 2016.

Episódios de Modelagem sobre oscilações mecânicas, fluidos e termodinâmica. 2015. Disponível em: <http://www.if.ufrgs.br/gpef/modelagem/hipermidia/>. Acesso em: 01 nov. 2015.

; SILVEIRA, F. L. Um Ciclo de Modelagem sobre a Lei de Resfriamento de Newton. In: SIMPÓSIO NACIONAL DE ENSINO DE FÍSICA, XX, 2013, Curitiba. Atas... São Paulo: 2013.

HESTENES, D. Notes for a Modeling Theory of Science, Cognition and Instruction. In: GIREP CONFERENCE: MODELLING IN PHYSICS AND PHYSICS EDUCATION, Amsterdam, Netherlands, 2006.

HODSON, D. Hacia un enfoque más crítico del trabajo de laboratorio. Enseñanza de las Ciencias, Barcelona, v.12, n. 3, p. 299-313, nov.1994.

HOFMANN, M. P. Determinação da composição de uma liga metálica. Caderno Catarinense de Ensino de Física, Florianópolis, v. 4, n. 2, p. 112-113, ago. 1987. 
JUSTI, R.; GILBERT, J. K. Modelling, teachers' view on the nature of modelling, and implications for the education of modellers. International Journal of Science Education, Philadelphia, v. 24, n. 4, p. 369-87, April 2002.

KOPONEN, I. T. Models and modelling in Physics Education: A critical re-analysis of philosophical underpinnings and suggestions for revisions. Science \& Education, New York, v. 16, n. 7, p. 751-773, Aug. 2007.

LOUCA, L; ZACHARIA, Z. Modeling-based learning in Science education: cognitive, metacognitive, social, material and epistemological contributions. Educational Review, Philadelphia, v. 64, n. 4, p. 471-492, Nov. 2012.

MARTINS, R. A. Arquimedes e a coroa do rei: Problemas históricos. Caderno Brasileiro de Ensino de Física, Florianópolis, v. 17, n. 2, p. 115-121, ago. 2000.

MATTHEWS, M. Ancient and medieval timekeeping. In: Time for science education: how teaching the history and philosophy of pendulum motion can contribute to science literacy. New York: Springer, 2000. cap. 3. p 47-76.

MAZUR, E. Peer Instruction: A User's Manual. Upeer Saddle River: Prentice Hall, 1997.

OH, P. S.; OH, S. J. What teachers of science need to know about models: An overview. International Journal of Science Education, Philadelphia, v. 33, n. 8, p. 1109-1130, May 2011.

OTERO, M. R. Emociones, sentimientos y razonamientos en didáctica de las Ciencias. Revista Electrónica de Investigación en Educación en Ciencias, Tandil, v. 1, n. 1, p. 24-53, oct. 2006.

PIETROCOLA, M. Construção e realidade: o realismo científico de Mario Bunge e o ensino de ciências através de modelos. Investigações em Ensino de Ciências, Porto Alegre, v. 4, n. 3, p. 213-227, set. 1999.

SETTLE, T. B. An experiment in the history of Science. Science, Washington, v. 133, n. 3445, p. 19-23, Jan. 1961.

SILVEIRA, F. L.; MEDEIROS, A. O paradoxo hidrostático de Galileu e a lei de Arquimedes. Caderno Brasileiro de Ensino de Física, Florianópolis, v. 26, n. 2, p. 273-294, ago. 2009.

TRUMPER, R. The physics laboratory: a historical overview and future perspectives. Science \& Education, New York, v. 12, n. 7, p. 645-670, Oct. 2003.

VERGNAUD, G. Teoria dos campos conceituais. In: SEMINÁRIO INTERNACIONAL DE EDUCAÇÃO MATEMÁTICA DO RIO DE JANEIRO, 1, 1993, Rio de Janeiro. Anais..., 1993. p. 1-26. 
. A trama dos campos conceituais na construção dos conhecimentos. Revista do GEMPA, Porto Alegre, n. 4, p. 9-19, 1996

. Towards a cognitive theory of practice. In: Kilpatrick, J.; Sierpinska, A. K. (Eds.). Mathematics Education as a Research Domain: a search of identity. New York: Kluwer Academic Publishers, 1997. p. 227-240.

A comprehensive theory of representation for mathematics education. Journal of Mathematical Behavior, Amsterdam, v.17, n. 2, p.167-181, 1998.

The theory of conceptual fields. Human Development, Basel, v. 52, n. 2, p. 8394, 2009.

Forme opératoire et forme prédicative de la connaissance. Investigações em Ensino de Ciências, Porto Alegre, v. 17, n. 2, p. 287-304, 2012.

Conceptual development and learning. Revista Qurriculum, San Cristóbal de La Laguna, v. 26, p. 39-59, marzo 2013 a.

- ¿Por qué la teoría de los campos conceptuales? Infancia y Aprendizaje, Madrid, v. 36, n. 2, p. 131-161, 2013b.

. Las competencias, ¡bravo! Pero, ¿y luego? Reflexiones críticas para avanzar. In:

Uribe, J. V. E. et al. (Org.). ¿Qué demonios son las competencias? Aportaciones del constructivismo clásico y contemporâneo. Veracruz: Universidad Veracruzana, 2014. cap. XIII, p. 365 